\title{
Empirical Modelling of Household Oils in UV-Vis-NIR Spectrum through Developed Low-Cost Spectroscopy Setup (LCSS)
}

\section{Amit Kumar Shakya}

SLIET: Sant Longowal Institute of Engineering and Technology

surinder singh ( $\nabla$ surinder_sodhi@rediffmail.com )

Sant Longowal Institution of Engg. \& Technology, Longowal, Sangrur, Punjab https://orcid.org/00000001-6348-1743

\section{Research Article}

Keywords: LCSS, transmission, absorbance, olive oil, mustard oil, amla oil, red palm oil.

Posted Date: October 18th, 2021

DOI: https://doi.org/10.21203/rs.3.rs-874867/v1

License: (c) (1) This work is licensed under a Creative Commons Attribution 4.0 International License.

Read Full License 


\section{Empirical Modelling of Household Oils in UV-Vis-NIR Spectrum through Developed Low-Cost Spectroscopy Setup (LCSS)}

Amit Kumar Shakya, Surinder Singh*

Department of Electronics and Communication Engineering

Sant Longowal Institute of Engineering and Technology, Sangrur, Punjab, India

Email: surinder_sodhi@ rediffmail.com

Abstract: In this research work, a low-cost $U V-V i s-N I R$ spectroscopy setup (LCSS) is developed and presented to analyze transmission (\%) and absorption ( $A u$ ) from household oils samples. The sensing potential of the developed setup is examined using four different oil samples. These oil samples consist of olive oil, mustard oil, amla oil, and red palm oil. The transmission (\%) obtained for olive oil, mustard oil, amla oil, and red palm oil is $75.66 \%$, $71.10 \%, 69.87 \%$, and $68.12 \%$ at $923.2 \mathrm{~nm}, 924.5 \mathrm{~nm}, 925.9 \mathrm{~nm}$, and $927.8 \mathrm{~nm}$ respectively. Similarly, the absorbance $(A u)$ for olive oil, mustard oil, amla oil, and red palm oil is $0.121 \mathrm{Au}, 0.141 \mathrm{Au}, 0.153 \mathrm{Au}$, and $0.163 \mathrm{Au}$ at $920.0 \mathrm{~nm}, 923.0 \mathrm{~nm}, 925.8 \mathrm{~nm}$, and $930.2 \mathrm{~nm}$ respectively. A linear relationship in the wavelength range of $920 \mathrm{~nm}$ to $935 \mathrm{~nm}$ between transmission (\%) and wavelength produce $R^{2}=0.9717$ corresponding to a degree (2). Similarly, the linear relation between absorbance $(A u)$ and wavelength produce $R^{2}=$ 0.9997 corresponding to a degree (2). Finally, an $8^{\text {th }}$ order empirical sinusoidal model is developed for transmission (\%) and absorbance $(A u)$ corresponding to the olive oil, mustard oil, amla oil, and red palm oil. The maximum value of $R$-square corresponding to the transmission (\%) for the developed empirical model is obtained for amla oil. Similarly, the full value of the absorbance $(A u)$ from the developed empirical model is obtained for red palm oil, which indicates a great response towards the empirical sinusoidal model.

Keywords: LCSS, transmission, absorbance, olive oil, mustard oil, amla oil, red palm oil.

\section{Introduction}

Several sensing setups and spectroscopes developed to date to analyze liquids, biochemical, bioanalytes, etc., based on transmission (\%) and absorbance $(A u)$. Some of the prominent sensing setups developed in optical physics consist of "curvature sensing setup" based on fiber laser and gratings [1], "displacement and curvature sensing setup" based on the "Fabry-Perot interferometer" [2], sensing setup to identify the amount of torsion based on a "three-beam path Mach-Zehnder interferometer" [3] and so on. In this research, a novel low-cost spectroscopy setup (LCSS) is developed and presented inspired by traditional spectroscopy devices. The developed setup identifies the behavior light entering and leaving the sample solution. The light 
transmitted by the sample solution is known as "transmission." The amount of light absorbed by the sample solution is known as the "absorbance" of the sample solution. The sample solutions investigated in this research work are common household oils used in most kitchens all around the World. The sample household oils consist of olive oil, mustard oil, amla oil, and red palm oil. These oil samples consist of different chemical compositions thus have distinct behavior corresponding to light of $200 \mathrm{~nm}$ to $1200 \mathrm{~nm}$. Analyzing the transmission and absorbance from the oils sample assists in identifying the concentration of different oils, which can be used as a "new standard for quality evaluation" of the household oils.

In the last few decades use of photonic devices in optical communication setups, biosensing apparatus, wavelength division multiplexing (WDM), spectroscopy analysis, physical parameter sensing [4] [5], etc., have tremendously increased. Among the above applications, fiber lasers are extensively used for physical parameter sensing. The sensing setup through which the interaction of light with a sample is analyzed mainly depends on its photophysical properties. Today several biosensing setups have developed, like fluorescent sensors [6], electrochemiluminescence sensors [7], dynamic light scattering sensors [8], surface-enhanced Raman scattering sensors [9], colorimetric sensors [10], and surface plasmon resonance sensors [11], [12]. The primary principle of these sensing devices is the "light" and "sample" interaction.

The proposed setup is designed to operate in $U V-V i s-N I R$ range. The $U V$ region lies in the wavelength range of $10 \mathrm{~nm}-400 \mathrm{~nm}$ [13]. This range can be further divided into three different bands, i.e., $\quad \operatorname{UVA}(315 \mathrm{~nm}-400 \mathrm{~nm}), \quad U V B(280 \mathrm{~nm}-315 \mathrm{~nm})$ and $U V C(100 \mathrm{~nm}-280 \mathrm{~nm})$ [14]. The range of the visible spectrum is $400 \mathrm{~nm}-700 \mathrm{~nm}$ approximately [15]. Finally, the wavelength range of the NIR spectrum lies in the interval $750 \mathrm{~nm}$ to $2500 \mathrm{~nm}$ [16] Since the proposed spectroscope is designed to operate in the wavelength range of $200 \mathrm{~nm}-1200 \mathrm{~nm}$, thus its operational range lie in the $U V-V i s-$ NIR region.

Spectroscopes designed in the $U V-V i s-N I R$ range can determine the spectral properties of liquids and solids in a wide range. These devices can quantify the amount of analytes present in a solution. These devices provide "quality control" and "quality assurance." The spectroscopes working in $U V-V i s-N I R$ range possess some advantages and shortcomings. Advantages of spectroscopes designed in the $\mathrm{UV}-\mathrm{Vis}-\mathrm{NIR}$ range.

- The concentration of a wide variety of analytes in a solution can be examined in this wavelength range. 
- Analytes quantification in a solution using this $U V-V i s-N I R$ spectroscopy technique is less time-consuming and easier than chromatographic analysis.

\section{Shortcoming of spectroscopes designed in the $U V-V i s-N I R$ range}

- Unwanted components in a solution can affect the sensing process.

- Methods based on chromatographic analysis have shown more accuracy and preciseness as compared to $U V-V i s-N I R$ spectroscopy.

- Selection of sample size, sample volume has their specific requirement and challenges. The article is organized into four sections. Section (2) presents the background principle of calculating transmission and absorbance from the liquids samples. Section (3) offers the details of the developed LCSS and experimental results. Finally, section (4) presents the concluding remarks on the research work.

\section{Background principle of the proposed LCSS}

Beer lambert law states that when monochromatic light is passed through a sample solution, the rate of decrease in the intensity with the thickness of the medium is proportional to the intensity of the light. In optics, quantification of the photons numbers delivered at a particular point at some specific time interval is known as "light intensity." In ordinary perception, "bright light" corresponds to the high intensity of light, and "dimmer light" corresponds to light having low intensity [17]. If the light beam of intensity $\left(I_{i n}\right)$ is entering the sample and the light beam of intensity $\left(I_{\text {out }}\right)$ is leaving the sample [18]. The relation of change in the light intensity concerning the path length of the sample holder is expressed by Equation $(1-9)$.

$$
\begin{aligned}
& -\frac{d I}{d l} \propto I \\
& -\frac{d I}{d l}=\alpha I \\
& -\frac{d I}{I}=\alpha d l \\
& -\int_{I_{\text {out }}}^{I_{\text {in }}} \frac{d I}{I}=\int \alpha d l \\
& -[\log (I)]_{I_{\text {out }}}^{I_{\text {in }}}=\alpha L \\
& \log \left(I_{\text {in }}\right)-\log \left(I_{\text {out }}\right)=-\alpha L \\
& \log \left(\frac{I_{\text {in }}}{I_{\text {out }}}\right)=-\alpha L
\end{aligned}
$$


$\left(\frac{I_{\text {in }}}{I_{\text {out }}}\right)=e^{-\alpha L}$

$I_{\text {in }}=I_{\text {out }} e^{-\alpha L}$

The phenomenon of the incoming and outgoing light flow from the sample solution can be understood from Figure (1). Thus, the ratio of light "entering" the sample and light "leaving" the sample is defined as "Transmission." It can be expressed by Equation (10). It is a unitless quantity [19].

Transmission $=\left(I_{\text {in }} / I_{\text {out }}\right)[$ Unitless $]$

The transmission in percentage is expressed by Equation (11) [5].

$\operatorname{Transmission}(\%)=\left(I_{\text {in }} / I_{\text {Out }}\right) \times 100$

Indeed, the amount of light leaving the sample will have a low intensity than the intensity of light entering the sample. Thus the amount of light lost in between entering and leaving the sample is known as the "absorbance" of the sample solution. It is assigned a unit $(A u)$ known as an arbitrary unit. Different sample solutions can have different absorbance values. It is expressed by Equation (12) [20].

Absorbance $(A b)=-\log _{10} \frac{I_{\text {in }}}{I_{\text {Out }}}[A u]$

When a light beam of a convenient wavelength $(\mathrm{nm})$ is passed through some dilute solution, the light photons absorbed by the solution will be small, but certainly, some light photons will be absorbed. This results in "high transmission" and "low absorbance." Similarly, when a light beam is passed through a concentrated solution. The number of photons absorbed will be high as compared to the dilute solution. Thus, in this case, "low transmission" and "high absorbance" are recorded. Therefore "transmission" and "absorbance" both depend upon the concentration of the sample solution.

Absorbance is also related to the "length of the path" in which the sample solution is present. It is expressed by Equation (13) [21].

Absorbance $=k_{l} \times p_{l} \times c$

Where $k_{l}$ is the constant of proportionality, $p_{l}$ is defined as the path's length, and " $c$ " is the solution's concentration under investigation. This technique is an adaption of the "BeerLambert Law" [22].

The pictorial representation of the sensing methodology for the proposed LCSS is presented in Figure (1). The amount of light leaving the light source is $I_{\text {in }}$ which travel through an optical 
fiber to the sample holder. The amount of light leaving is sample holder is $I_{\text {out }}$ which is measured through a spectrometer and is presented on the computer screen as output. While performing the practical experimentation, it is essential to note that atmospheric disturbance always affects the sensing process. Therefore, the transmission and absorbance parameters are likewise affected, and thus the modified transmission and absorbance are expressed by Equation (14) and Equation (15).

$\operatorname{Transmission}(\%)=\left(I_{\text {in }}-I_{\text {Dark }} / I_{\text {Out }}-I_{\text {Dark }}\right)$

Absorbance $(A b)=-\log _{10} \frac{I_{\text {in }}-I_{\text {Dark }}}{I_{\text {Out }}-I_{\text {Dark }}}$

Where $I_{\text {Dark }}$ is the atmospheric disturbance generated during the sample testing process, which is extracted from the experimental method.

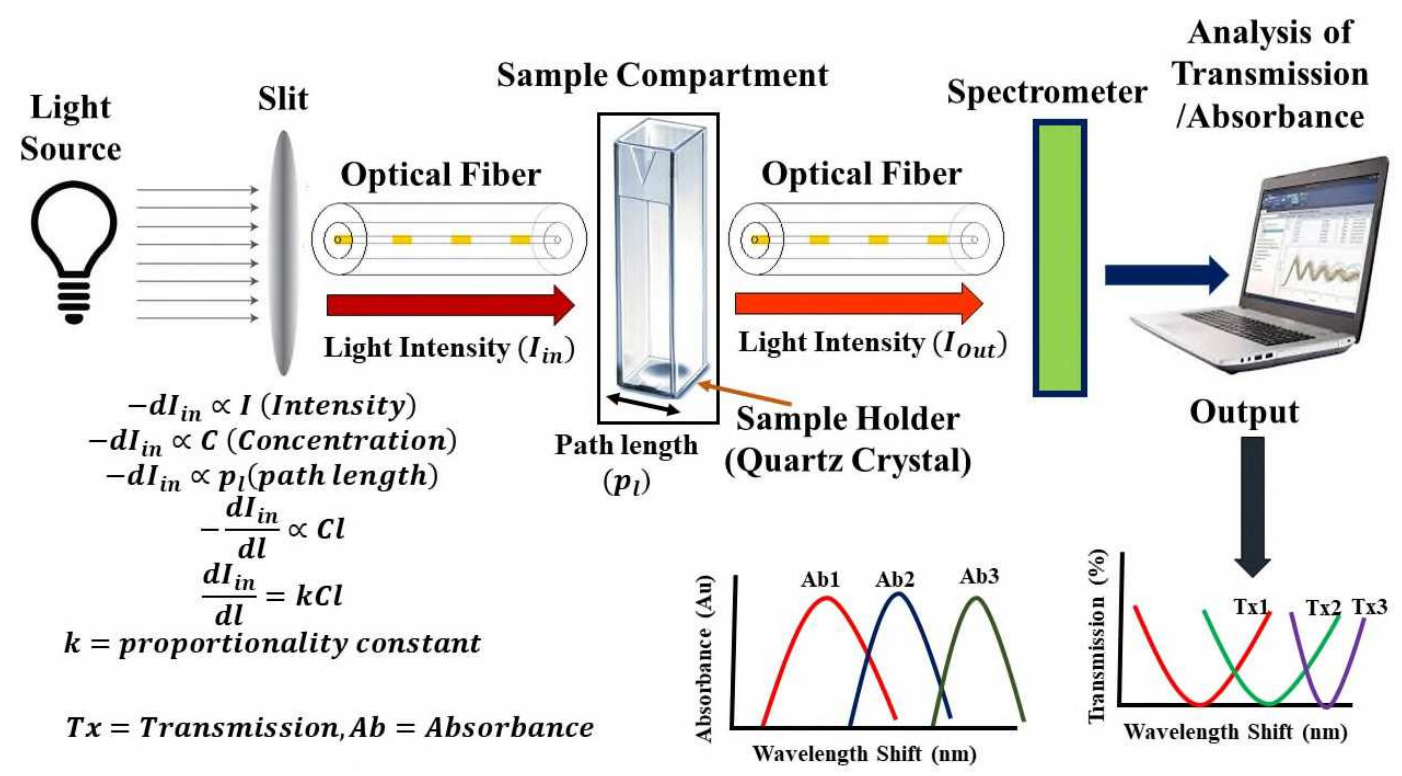

Figure 1: Block diagram for analyzing transmission and absorbance from the sample

\section{Experimental Results}

The LCSS presented in this research work measures the incoming and outgoing light through the sample. This sample can be water, fluid, chemicals, anything but in liquid form. The LCSS main components are halogen light source, sample compartment, sample cuvettes, spectrometer, and connecting optical fiber. The output received from the spectrometer is transferred to the computer screen using a $U S B$ cable. The light source is a "stabilized tungsten halogen light source" which can operate in the wavelength range of $360-2600 \mathrm{~nm}$. Its operational temperature is $4.5^{\circ} \mathrm{C}$ to $35^{\circ} \mathrm{C}$. The sample compartment is a black-colored solid metallic chamber that prevents the sample from atmospheric disturbances and interferences. 
The sample holder is a hollow cuboidal tube made up of quartz material. The cuvette is having a $10 \mathrm{~mm}$ path length and has a volume of $3500 \mu \mathrm{l}$. It is having a dimension of $45 \mathrm{~mm} \times$ $12.5 \mathrm{~mm} \times 12.5 \mathrm{~mm}$. While analyzing a sample solution, it is essential to note that the cuvette should be filled minimum of up to $50 \mu \mathrm{l}$ the for correct reading. The cuvette needs to be rinsed with the distilled water every time after a sample is analyzed. The spectrometer is a "chargecoupled device (CCD)" having a linear array detector with 3648 pixels. It can operate with a total capacity up to $0.03 \mathrm{~nm}$ "full-wave half maximum (FWHM). The spectrometer system consists of a focusing optical system, dispersion element (grating), collimating mirror, incident slit, and a detector. All the components are connected with the assistance of optical fiber. The light is passed into the spectrometer device through the optical fiber. Lastly, a USB cable is connected with a computer system in which the data from the spectrometer is received after analyzing sample solutions. Finally, the spectral information collected is represented in transmission $(\%)$ and absorbance $(A u)$ corresponding to the different oil samples. In this case, different oil samples are analyzed from the setup. The components of the developed LCSS consist of a halogen light source, sample compartment, sample holder, and spectrometer purchased from "Research India" Bhopal, India [23]. The optical fiber cable used in the proposed LCSS is M93L01 stainless steel fiber patch cable purchased from the "THOR lab" New Jersey, United States [24]. Finally, the oil samples used in this work are obtained from the local vendors of the Longowal, Punjab, India [25]. The oils investigated through the sensing setup includes olive oil, mustard oil, amla oil, and red palm oil, as presented in Figure 2 (b).

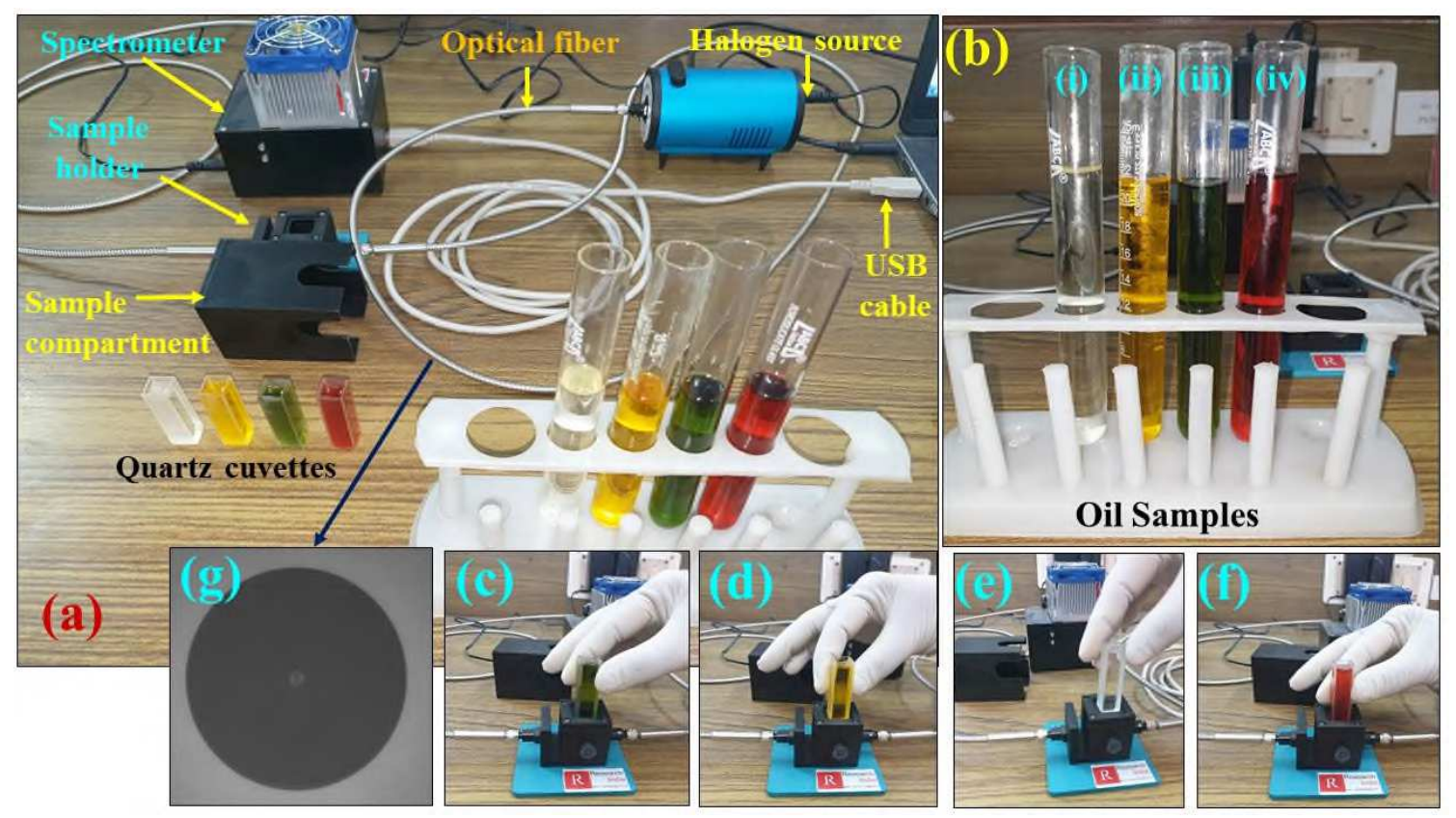


Figure 2: (a) LCSS developed to analyze common household oils (b) (i) Olive oil (ii) Mustard oil (iii) Amla oil (iv) Red palm oil; Quartz cuvettes with oil samples (c) Amla oil (d) Mustard oil (e) Olive oil (f) Red palm oil (g) 2D cross-section of the M93L01 optical fiber

Oil sample (1) is olive oil presented in Figure 2 (b-i), in which contamination is externally added in many forms like the mixing of refined vegetable oils (dilution), the addition of coloring additive (unauthorized enhancement), mixing deep-fried used oil [26]. These contaminations affect the concentration of olive oil. Oil sample (2) consists of mustard oil presented in Figure 2 (b-ii). It is reddish-brown or amber in color. Mustard oil is the main component of the Indian kitchen. Adulteration in mustard oil with fried mustard oil causes a potential threat to the health of the consumers. The fried mustard oil consists of polyunsaturated fatty acids, which affect the concentration of the mustard oil [27]. Oil sample (3) consists of amla oil presented in Figure 2 (b-iii). This oil is dark green. Amla is popularly known as Indian gooseberry. It is classified in various categories as native gooseberry, wild gooseberry, etc. Cape gooseberry is a fruit that is having high demand throughout the World. Amla oil is also degraded by various chemicals and additives, which affect the oil sample concentration [28]. Oil sample (4) is presented in Figure 2 (b-iv), which consists of red palm oil that is very nutritious. In many research, it has been proved that it has similar qualities to milk. It is considered a good supplement for pregnant women. There are several methods through will red palm oil is adulterated. At the same time, this oil is also used as an adulteration agent. Thus the concentration of the red palm is degraded by various methods and toxic substances [29].

\section{A. Analysis of the spectral behavior of the oil sample}

The spectral behavior of the transmission (\%) and absorbance $(A u)$ from different household oil samples is analyzed from the developed LCSS.
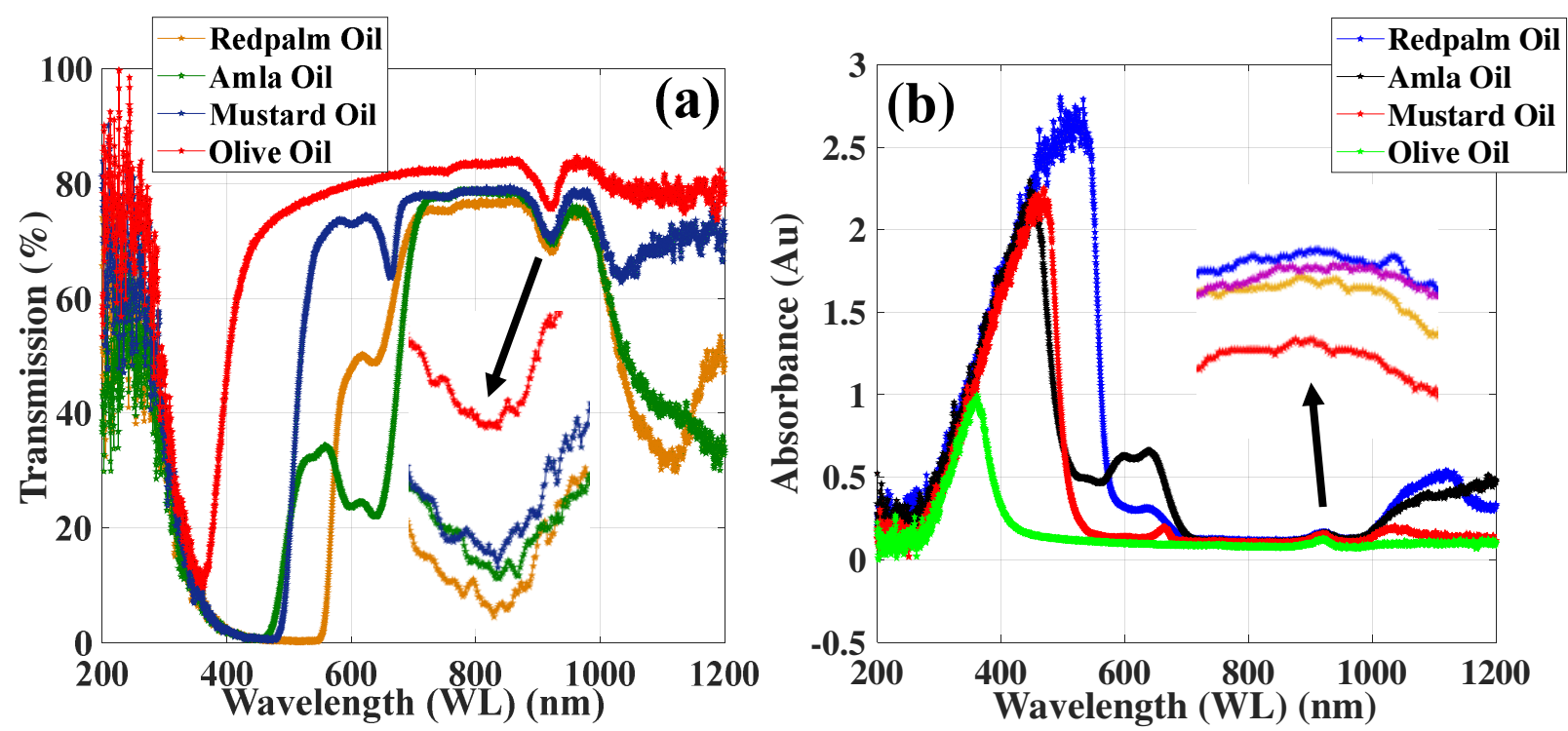
Figure 3 (a) Transmission (\%) corresponding to different oil samples (b) Absorbance ( $A u$ ) corresponding to different oil samples

Figure (3) presents the outcome of the spectroscopy analysis of olive oil, mustard oil, amla oil, and red palm oil samples for the wavelength range of $200 \mathrm{~nm}$ to $1200 \mathrm{~nm}$. It can be observed from Figure 3 (a) that all four oil samples are responding differently under the same conditions. Olive oil has obtained a transmission $(\%)$ of $11.58 \%, 82.35 \%, 75.66 \%$, and $78.77 \%$ at a wavelength of $357.9 \mathrm{~nm}, 758.7 \mathrm{~nm}, 923.2 \mathrm{~nm}$, and $1020 \mathrm{~nm}$ respectively. Transmission (\%) of $0.5851 \%, 73.29 \%, 64.37 \%$, and $71.10 \%$ is obtained at the wavelength of $471.8 \mathrm{~nm}$, $592.6 \mathrm{~nm}, 666.2 \mathrm{~nm}$, and $925.5 \mathrm{~nm}$ respectively corresponding to the mustard oil.

Amla oil has obtained a transmission $(\%)$ of $32.18 \%, 24.54 \%, 22.18 \%$, and $69.87 \%$ at the wavelength of $532.3 \mathrm{~nm}, 590.3 \mathrm{~nm}, 636.1 \mathrm{~nm}$, and $922.9 \mathrm{~nm}$ respectively. Transmission (\%) of $48.77 \%, 75.19 \%, 68.12 \%$, and $71.79 \%$ is obtained at the wavelength of $634.9 \mathrm{~nm}$, $754.1 \mathrm{~nm}, 924.9 \mathrm{~nm}$, and $933.5 \mathrm{~nm}$ respectively corresponding to the red palm oil. It has been observed that in the wavelength range of $920 \mathrm{~nm}$ to $935 \mathrm{~nm}$ all the oils have obtained a change in the transmission $(\%)$.

Figure 3 (b) represents the change in the absorbance behavior of all oil samples responding differently under the same conditions.

Olive oil has obtained an absorbance $(A u)$ of $0.968 A u, 0.092 A u, 0.095 A u$, and $0.121 A u$ at the wavelength of $358.7 \mathrm{~nm}, 651.7 \mathrm{~nm}, 900.7 \mathrm{~nm}$, and $920 \mathrm{~nm}$ respectively.

Absorbance $(A u)$ of $2.142 A u, 0.194 A u, 0.105 A u$, and $0.141 A u$ is obtained at a wavelength of $466.4 \mathrm{~nm}, 663.1 \mathrm{~nm}, 857.1 \mathrm{~nm}$, and $920.8 \mathrm{~nm}$ respectively for the mustard oil.

Amla oil has obtained absorbance $(A u)$ of $2.219 A u, 0.491 A u, 0.654 A u$, and $0.153 A u$ at a wavelength of $447.2 \mathrm{~nm}, 539.2 \mathrm{~nm}, 642.2 \mathrm{~nm}$, and $925.8 \mathrm{~nm}$ respectively.

Absorbance $(A u)$ of $2.647 A u, 0.309 A u, 0.146 A u$, and $0.163 A u$ at a wavelength of $519.6 \mathrm{~nm}, 639.4 \mathrm{~nm}, 911.4 \mathrm{~nm}$, and $930.2 \mathrm{~nm}$ respectively is obtained corresponding to the red palm oil.

Table 1: Transmission and absorbance of the household oil samples

\begin{tabular}{|l|c|c|c|c|c|c|}
\hline S.No & $\begin{array}{c}\text { Oil } \\
\text { Sample }\end{array}$ & $\begin{array}{c}\text { Wavelength } \\
(\boldsymbol{n m})\end{array}$ & $\begin{array}{c}\text { Transmission } \\
(\boldsymbol{\%})\end{array}$ & $\begin{array}{c}\text { Wavelength } \\
(\boldsymbol{n m})\end{array}$ & $\begin{array}{c}\text { Absorbance } \\
(\boldsymbol{A U})\end{array}$ & $\begin{array}{c}\text { Shift in } \\
\text { wavelength } \\
(\boldsymbol{n m})\end{array}$ \\
\hline 1 & Olive oil & 923.2 & 75.66 & 920.0 & 0.121 & 3.2 \\
\hline 2 & Mustard oil & 924.5 & 71.10 & 923.0 & 0.141 & 1.5 \\
\hline 3 & Amla oil & 925.9 & 69.87 & 925.8 & 0.153 & 0.1 \\
\hline 4 & Redpalm oil & 927.8 & 68.12 & 930.2 & 0.163 & 2.4 \\
\hline
\end{tabular}


A linear relationship between the wavelength $(\mathrm{nm})$, transmission $(\%)$, and absorbance $(A u)$ is essential for device optimization. Table (1) represents the transmission (\%) and absorbance (Au) corresponding to the different oil samples in the wavelength range of $920 \mathrm{~nm}$ to $935 \mathrm{~nm}$. The linear fitting of degree (1) and degree (2) between the wavelength and transmission (\%) is presented in Figure 4 (a \& b), respectively. Similarly, the linear fitting of degree (1) and degree (2) between the wavelength and absorbance $(A u)$ is presented in Figure 4 (c \& d), respectively. The goodness of the curve fitting is obtained with a $95 \%$ confidence bound. Conventional fitting parameters like "sum of squared error $(S S E)$, , " $R$ - square," “Adjusted R-Square," and "root means square error (RMSE)" are obtained and tabulated in Table (2).
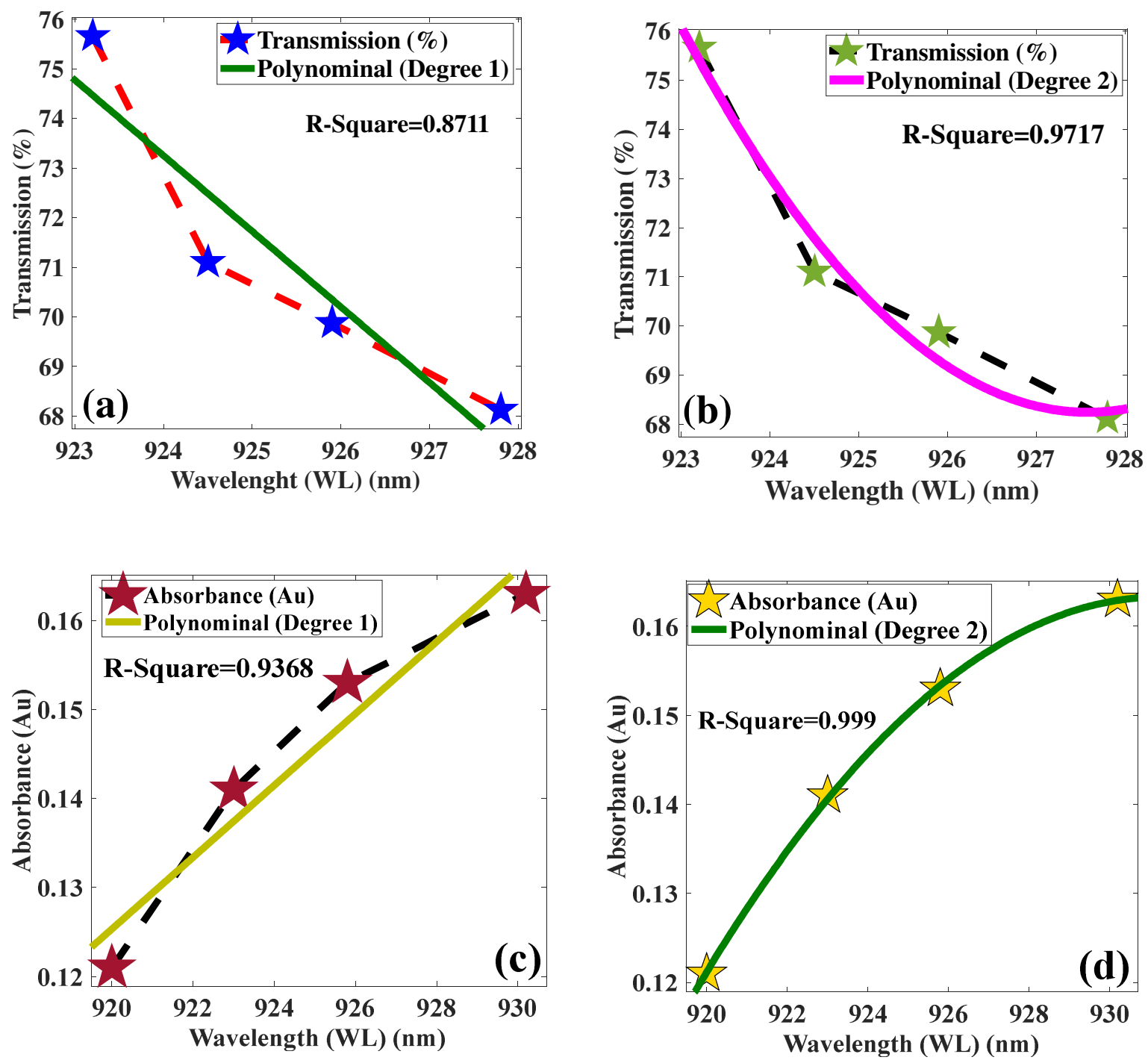

Figure 4: Polynomial fitting between the transmission (\%) vs. wavelength (a) degree (1) (b) degree (2); Polynomial fitting between the absorbance $(A U)$ vs. wavelength (c) degree (1) (d) degree (2) 
Table 2: Fitting parameters for transmission $(\%)$ and absorbance $(A u)$ corresponding to the wavelength $(920 \mathrm{~nm}-935 \mathrm{~nm})$

\begin{tabular}{|c|c|c|c|c|c|c|}
\hline \multirow{2}{*}{ S.No } & \multirow{2}{*}{ Variables } & \multirow{2}{*}{$\begin{array}{l}\text { Developed relationship between } \\
T x .(\%) \text { vs. wavelength } \\
\text { and } A b . \text { vs. wavelength }\end{array}$} & \multicolumn{4}{|c|}{$\begin{array}{l}\text { The goodness of the fitting parameters } \\
\text { (95\% confidence bound) }\end{array}$} \\
\hline & & & $R M S E$ & $\begin{array}{c}\text { Adjusted } \\
R-\text { Square }\end{array}$ & $\begin{array}{c}R- \\
\text { Square }\end{array}$ & $S S E$ \\
\hline 1 & $\begin{array}{c}T x . \text { vs. } \\
\text { wavelength } \\
\text { (Degree 1) }\end{array}$ & $\begin{array}{c}f(e q)=l_{1}(T x)+l_{2} \\
l_{1}=-1.526 \\
l_{2}=1484\end{array}$ & 1.417 & 0.8066 & 0.8711 & 4.016 \\
\hline 2 & $\begin{array}{c}T x . \text { vs. } \\
\text { wavelength } \\
\text { (Degree 2) }\end{array}$ & $\begin{array}{c}f(e q)=l(T x)^{2}+l_{2}(T x)+l_{3} \\
l_{1}=0.3734 \\
l_{2}=-692.7 \\
l_{3}=3.213 \times 10^{5}\end{array}$ & 0.9392 & 0.9151 & 0.9717 & 0.8822 \\
\hline 3 & $\begin{array}{c}A b . \text { vs. } \\
\text { wavelength } \\
\text { (Degree 1) }\end{array}$ & $\begin{array}{c}f(e q)=l_{1}(A b)+l_{2} \\
l_{1}=0.004032 \\
l_{2}=-3.584\end{array}$ & 0.00556 & 0.9053 & 0.9368 & $6.18 \times 10^{-5}$ \\
\hline 4 & $\begin{array}{c}A b . \text { vs. } \\
\text { wavelength } \\
\text { (Degree 2) }\end{array}$ & $\begin{array}{c}f(e q)=l_{1}(A b)^{2}+l_{2}(A b)+l_{3} \\
l_{1}=-0.003312 \\
l_{2}=0.6162 \\
l_{3}=-287.1\end{array}$ & 0.000568 & 0.999 & 0.9997 & $3.227 \times 10^{-7}$ \\
\hline
\end{tabular}

\section{B. Development of empirical model for Transmission and Absorbance}

In this section, empirical modeling is done corresponding to the spectrum plots of the oil samples. The empirical models are presented using $8^{\text {th }}$ order sinusoidal expression, which best fits the oil spectrums, with maximum fitting parameters. The developed model for the transmission and absorbance for the oil samples is presented in Equation (16).

$f(w l)=a_{1} \sin \left(b_{1} w l+c_{1}\right)+a_{2} \sin \left(b_{2} w l+c_{2}\right)+a_{3} \sin \left(b_{3} w l+c_{3}\right)+$

$a_{4} \sin \left(b_{4} w l+c_{4}\right)+a_{5} \sin \left(b_{5} w l+c_{5}\right)+a_{6} \sin \left(b_{6} w l+c_{6}\right)+a_{7} \sin \left(b_{7} w l+c_{7}\right)+$

$a_{8} \sin \left(b_{8} w l+c_{8}\right)$

The numerical values of the constant $a_{1} \ldots \ldots a_{8}, b_{1} \ldots \ldots b_{8}$, and $c_{1} \ldots \ldots \ldots c_{8}$ are tabulated in Table (3) corresponding to the transmission (\%). Figure (5) represents the sinusoidal fitting of $8^{\text {th }}$ order corresponding to transmission (\%) for different oil samples.

Table (3): Numerical values of the constant $a_{i}, b_{i}$, and $c_{i}$ for transmission (\%) $(1 \leq i \leq 8)$

\begin{tabular}{|c|c|c|c|c|c|c|c|c|c|}
\hline S.No & Oil & Nur & ical Constants & $\begin{array}{l}\text { Nur } \\
\text { Cor }\end{array}$ & $\begin{array}{l}\text { rical } \\
\text { ants }\end{array}$ & Num & al Constants & $\begin{array}{l}\text { Nur } \\
\text { Cor }\end{array}$ & \\
\hline 1 & \multirow{3}{*}{$\begin{array}{l}\overline{0} \\
\frac{\pi}{\tilde{g}} \\
\end{array}$} & $a_{1}$ & 68.14 & $a_{2}$ & 41.1 & $a_{3}$ & 14.56 & $a_{4}$ & 5.372 \\
\hline 2 & & $b_{1}$ & 0.002888 & $b_{2}$ & 0.005896 & $b_{3}$ & 0.01185 & $b_{4}$ & 0.01762 \\
\hline 3 & & $c_{1}$ & -0.2949 & $c_{2}$ & 1.723 & $c_{3}$ & -0.9662 & $c_{4}$ & -1.452 \\
\hline
\end{tabular}




\begin{tabular}{|c|c|c|c|c|c|c|c|c|c|}
\hline 4 & & $a_{5}$ & 9.358 & $a_{6}$ & 4.894 & $a_{7}$ & 1.933 & $a_{8}$ & 3.778 \\
\hline 5 & & $b_{5}$ & 0.0262 & $b_{6}$ & 0.04302 & $b_{7}$ & 0.02984 & $b_{8}$ & 0.03592 \\
\hline 6 & & $c_{5}$ & 0.5836 & $c_{6}$ & 3.005 & $c_{7}$ & -0.6262 & $c_{8}$ & 0.4505 \\
\hline 7 & \multirow{6}{*}{ 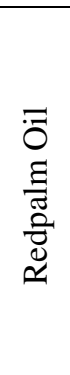 } & $a_{1}$ & 75.54 & $a_{2}$ & 34.41 & $a_{3}$ & 26.95 & $a_{4}$ & 3.933 \\
\hline 8 & & $b_{1}$ & 0.002512 & $b_{2}$ & 0.01011 & $b_{3}$ & 0.005222 & $b_{4}$ & 0.02323 \\
\hline 9 & & $c_{1}$ & -0.5199 & $c_{2}$ & -0.04321 & $c_{3}$ & 1.145 & $c_{4}$ & 4.316 \\
\hline 10 & & $a_{5}$ & 8.706 & $a_{6}$ & 4.176 & $a_{7}$ & 3.212 & $a_{8}$ & 3.061 \\
\hline 11 & & $b_{5}$ & 0.01618 & $b_{6}$ & 0.03504 & $b_{7}$ & 0.05278 & $b_{8}$ & 0.04345 \\
\hline 12 & & $c_{5}$ & -1.935 & $c_{6}$ & -1.311 & $c_{7}$ & -5.186 & $c_{8}$ & -4.835 \\
\hline 13 & \multirow{6}{*}{$\begin{array}{l}\overline{0} \\
0 \\
\overrightarrow{0}\end{array}$} & $a_{1}$ & 113.8 & $a_{2}$ & 38.67 & $a_{3}$ & 18.43 & $a_{4}$ & 17.61 \\
\hline 14 & & $b_{1}$ & 0.003082 & $b_{2}$ & 0.00614 & $b_{3}$ & 0.01307 & $b_{4}$ & 0.01836 \\
\hline 15 & & $c_{1}$ & -0.6446 & $c_{2}$ & 0.5957 & $c_{3}$ & -0.8439 & $c_{4}$ & -1.831 \\
\hline 16 & & $a_{5}$ & 10.45 & $a_{6}$ & 4.882 & $a_{7}$ & 22.68 & $a_{8}$ & 22.14 \\
\hline 17 & & $b_{5}$ & 0.02361 & $b_{6}$ & 0.03154 & $b_{7}$ & 0.04053 & $b_{8}$ & 0.04118 \\
\hline 18 & & $c_{5}$ & 3.315 & $c_{6}$ & 0.07165 & $c_{7}$ & -4.509 & $c_{8}$ & 4.374 \\
\hline 19 & \multirow{6}{*}{$\begin{array}{l}\overline{0} \\
\overline{0} \\
\overline{\tilde{J}} \\
\underline{\tilde{w}} \\
\sum\end{array}$} & $a_{1}$ & 446.1 & $a_{2}$ & 50.28 & $a_{3}$ & 327.9 & $a_{4}$ & 11.02 \\
\hline 20 & & $b_{1}$ & 0.001956 & $b_{2}$ & 0.008675 & $b_{3}$ & 0.003779 & $b_{4}$ & 0.02153 \\
\hline 21 & & $c_{1}$ & 1.496 & $c_{2}$ & 2.568 & $c_{3}$ & 3.406 & $c_{4}$ & -5.076 \\
\hline 22 & & $a_{5}$ & 8.37 & $a_{6}$ & 5.144 & $a_{7}$ & 6.45 & $a_{8}$ & 2.248 \\
\hline 23 & & $b_{5}$ & 0.02721 & $b_{6}$ & 0.03989 & $b_{7}$ & 0.0438 & $b_{8}$ & 0.07088 \\
\hline 24 & & $c_{5}$ & 5.712 & $c_{6}$ & 3.382 & $c_{7}$ & 2.959 & $c_{8}$ & -4.633 \\
\hline
\end{tabular}

Figure 5 (a-d) represents the fitting response of transmission (\%) against wavelength $(\mathrm{nm})$. The appropriate response suggests that a slight similarity is obtained in the spectral response of amla oil and red palm oil. Similarly, olive oil and mustard oil show little similarity in their spectral behavior.
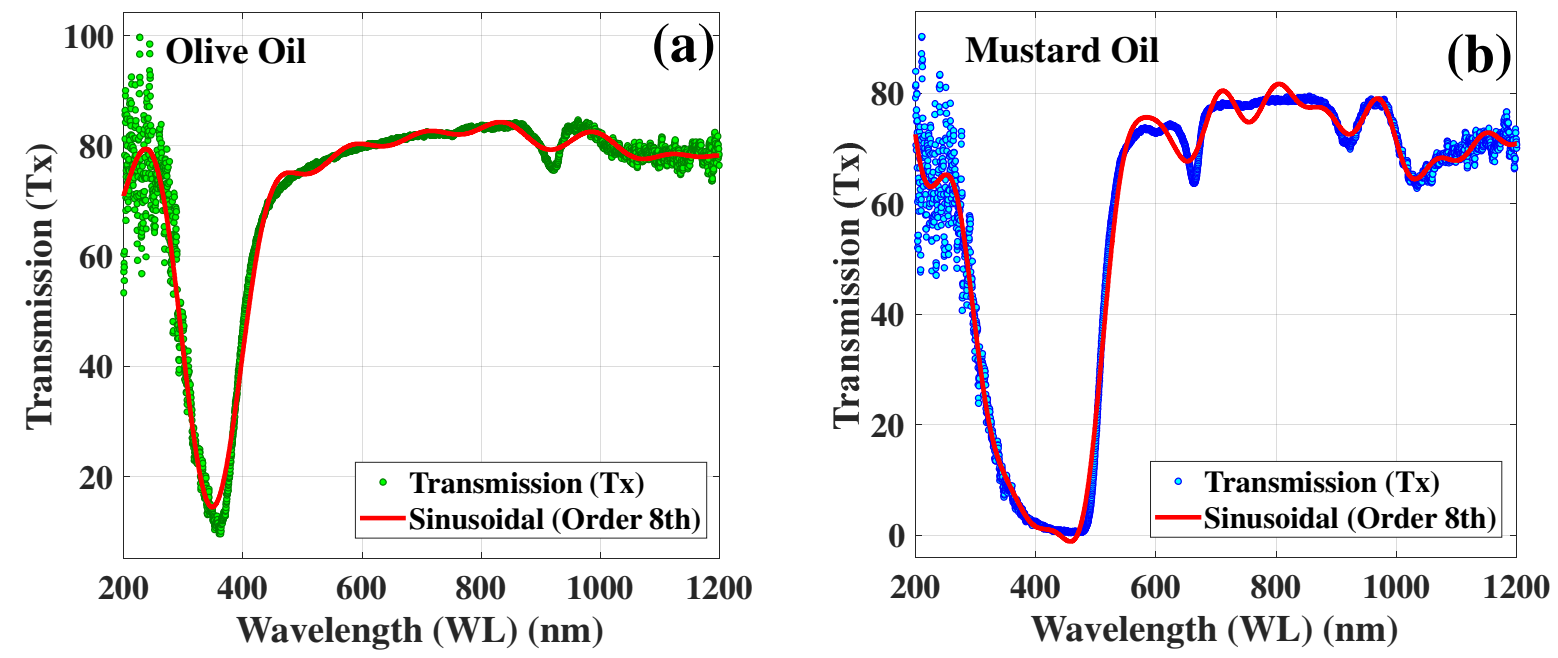

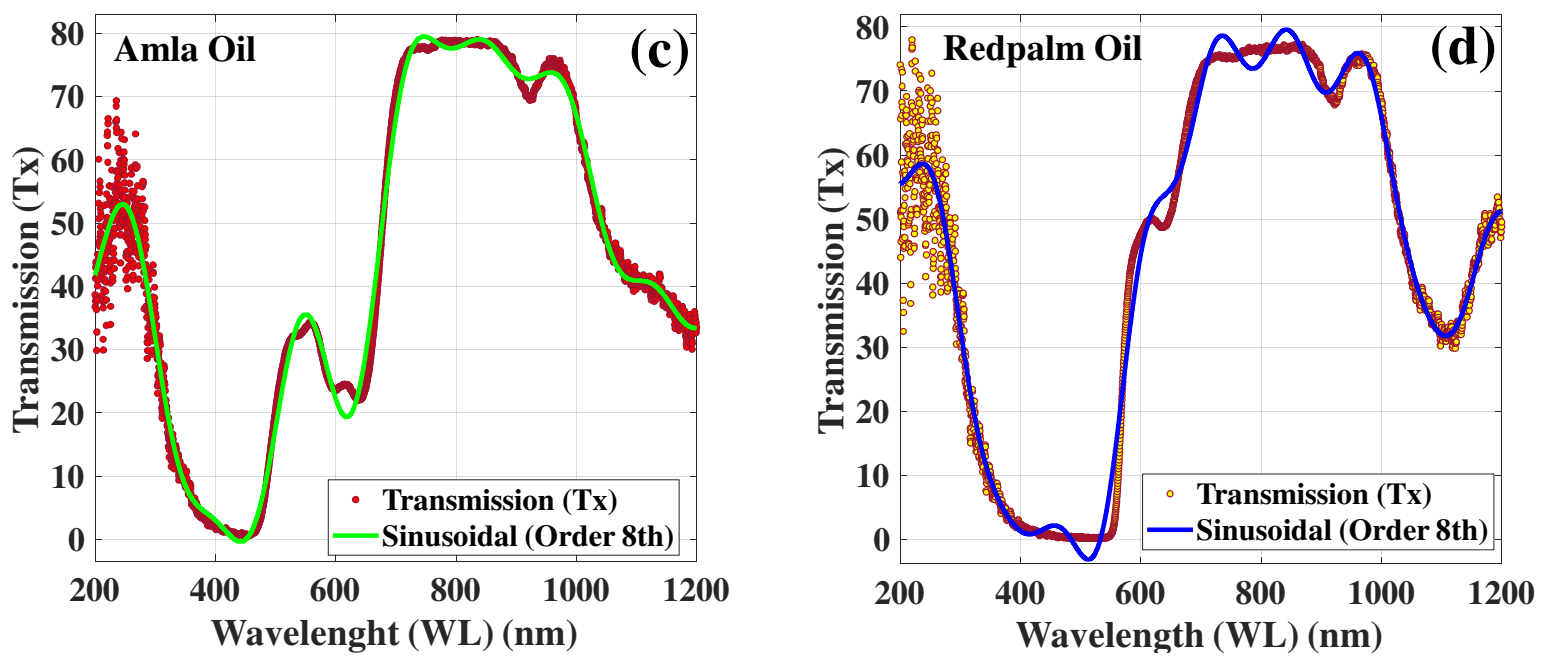

Figure 5: $8^{\text {th }}$ order sinusoidal fitting response corresponding to the transmission (\%) from the oil samples (a) Olive oil (b) Mustard oil (c) Amla oil (d) Red palm oil

Table (4) presents the values of the constant $a_{i}, b_{i}$, and $c_{i}$ where the range of $1 \leq i \leq 8$. It is corresponding to the absorbance $(A u)$.

Table (4): Numerical values of the constant $a_{i}, b_{i}$, and $c_{i}$ for absorbance $(A u)$

\begin{tabular}{|c|c|c|c|c|c|c|c|c|c|}
\hline S.No & Oil & $\begin{array}{l}\text { Num } \\
\text { Cons }\end{array}$ & $\begin{array}{l}\text { rical } \\
\text { ants }\end{array}$ & Num & cal Constants & Num & al Constants & $\begin{array}{l}\text { Num } \\
\text { Con }\end{array}$ & \\
\hline 1 & & $a_{1}$ & 0.863 & $a_{2}$ & 0.9099 & $a_{3}$ & 0.2769 & $a_{4}$ & 0.3036 \\
\hline 2 & & $b_{1}$ & 0.003202 & $b_{2}$ & 0.006192 & $b_{3}$ & 0.01186 & $b_{4}$ & 0.03012 \\
\hline 3 & $\overline{0}$ & $c_{1}$ & -1.055 & $c_{2}$ & -0.7239 & $c_{3}$ & 3.107 & $c_{4}$ & 2.346 \\
\hline 4 & $\vec{g}$ & $a_{5}$ & 0.1645 & $a_{6}$ & 0.3474 & $a_{7}$ & 0.2811 & $a_{8}$ & 0.2787 \\
\hline 5 & & $b_{5}$ & 0.01851 & $b_{6}$ & 0.0276 & $b_{7}$ & 0.04102 & $b_{8}$ & 0.04159 \\
\hline 6 & & $c_{5}$ & 0.3526 & $c_{6}$ & -4.616 & $c_{7}$ & -5.901 & $c_{8}$ & 2.75 \\
\hline 7 & & $a_{1}$ & 0.1613 & $a_{2}$ & 0.4638 & $a_{3}$ & 0.3234 & $a_{4}$ & 1.738 \\
\hline 8 & & $b_{1}$ & 0.003321 & $b_{2}$ & 0.0122 & $b_{3}$ & 0.01863 & $b_{4}$ & 0.005327 \\
\hline 9 & 呆 & $c_{1}$ & -1.387 & $c_{2}$ & 2.199 & $c_{3}$ & -1.372 & $c_{4}$ & -0.1587 \\
\hline 10 & 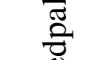 & $a_{5}$ & 0.2542 & $a_{6}$ & 0.1886 & $a_{7}$ & 0.1199 & $a_{8}$ & 0.8099 \\
\hline 11 & & $b_{5}$ & 0.02266 & $b_{6}$ & 0.03222 & $b_{7}$ & 0.0396 & $b_{8}$ & 0.04687 \\
\hline 12 & & $c_{5}$ & 3.525 & $c_{6}$ & -2.354 & $c_{7}$ & 0.09908 & $c_{8}$ & -3.931 \\
\hline 13 & & $a_{1}$ & 0.3032 & $a_{2}$ & 0.2111 & $a_{3}$ & 0.1076 & $a_{4}$ & 0.05381 \\
\hline 14 & & $b_{1}$ & 0.002584 & $b_{2}$ & 0.005054 & $b_{3}$ & 0.02349 & $b_{4}$ & 0.03112 \\
\hline 15 & $\overline{0}$ & $c_{1}$ & 0.08799 & $c_{2}$ & 1.028 & $c_{3}$ & 0.2926 & $c_{4}$ & -2.984 \\
\hline 16 & $\stackrel{2}{\overline{7}}$ & $a_{5}$ & 0.1509 & $a_{6}$ & 0.8476 & $a_{7}$ & 0.8426 & $a_{8}$ & 0.1022 \\
\hline 17 & & $b_{5}$ & 0.01913 & $b_{6}$ & 0.0408 & $b_{7}$ & 0.0408 & $b_{8}$ & 0.01475 \\
\hline 18 & & $c_{5}$ & 0.9361 & $c_{6}$ & 1.223 & $c_{7}$ & 1.223 & $c_{8}$ & -4.645 \\
\hline
\end{tabular}




\begin{tabular}{|c|c|c|c|c|c|c|c|c|c|}
\hline 19 & \multirow{6}{*}{$\begin{array}{l}\overline{0} \\
\bar{z} \\
\overline{\tilde{z}} \\
\tilde{z}\end{array}$} & $a_{1}$ & 0.7033 & $a_{2}$ & 0.3133 & $a_{3}$ & 0.4607 & $a_{4}$ & 0.7046 \\
\hline 20 & & $b_{1}$ & 0.001209 & $b_{2}$ & 0.01886 & $b_{3}$ & 0.01245 & $b_{4}$ & 0.005639 \\
\hline 21 & & $c_{1}$ & -0.2069 & $c_{2}$ & 0.01575 & $c_{3}$ & 2.609 & $c_{4}$ & -0.6599 \\
\hline 22 & & $a_{5}$ & 0.2437 & $a_{6}$ & 0.1732 & $a_{7}$ & 0.1146 & $a_{8}$ & 0.07167 \\
\hline 23 & & $b_{5}$ & 0.02738 & $b_{6}$ & 0.03225 & $b_{7}$ & 0.04326 & $b_{8}$ & 0.04685 \\
\hline 24 & & $c_{5}$ & -4.551 & $c_{6}$ & 0.3896 & $c_{7}$ & $\begin{array}{l}-6.4 \\
\end{array}$ & $c_{8}$ & -0.4682 \\
\hline
\end{tabular}

Figure (6) represents the $8^{\text {th }}$ order sinusoidal fitting corresponding to absorbance $(A u)$ for different oil samples. The absorbance plots of all the oil samples showed slight similarity in their spectrum curves, but the absorbance value differs for all oil samples.
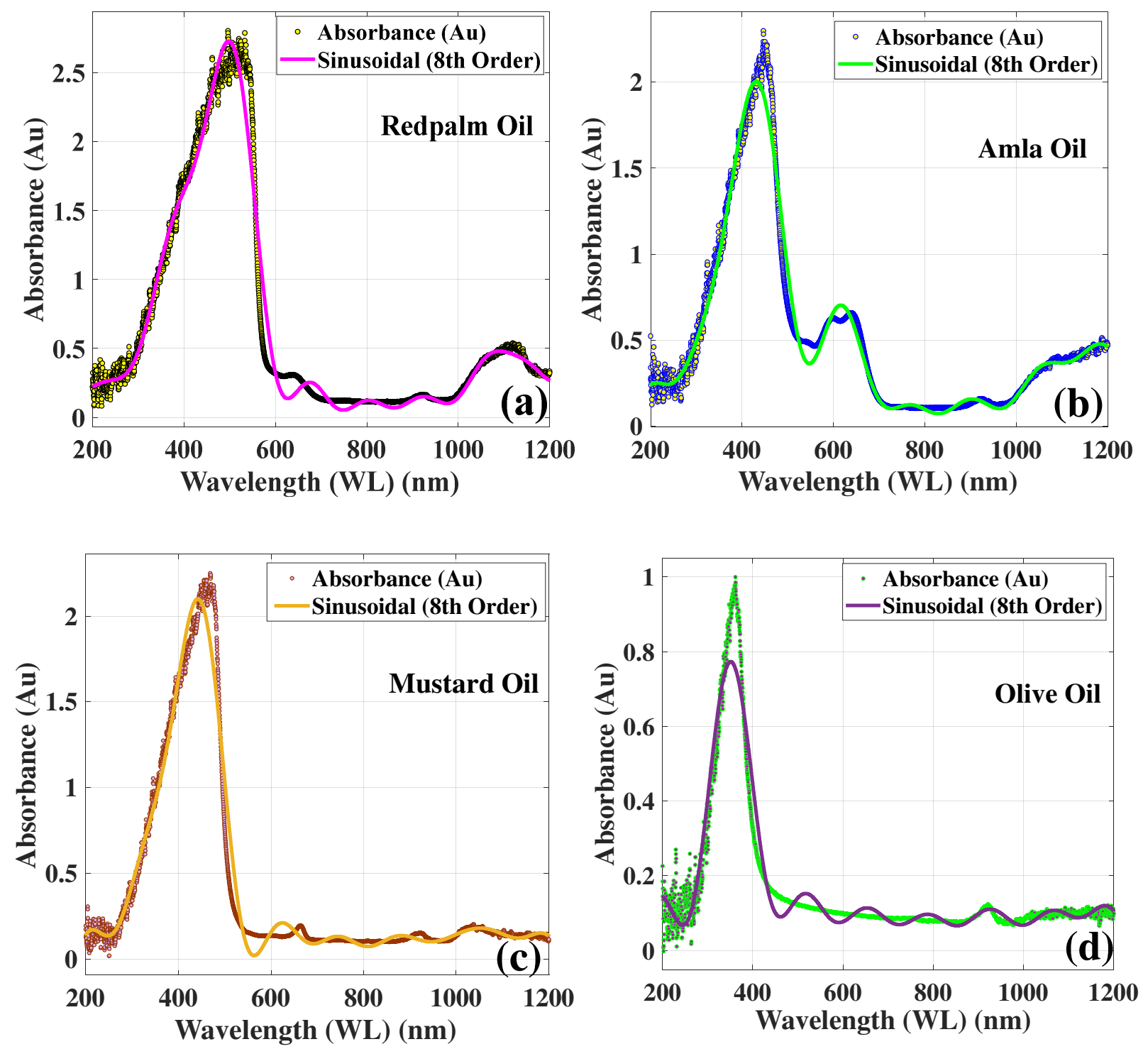

Figure 6: $8^{\text {th }}$ order sinusoidal fitting response corresponding to the absorbance $(A u)$ from the oil samples (a) Red palm oil (b) Amla oil (c) Mustard oil (d) Olive oil 
Sinusoidal fitting of the $8^{\text {th }}$ order is selected in this experiment because this curve fitting is closest to the ideal with good fitting values. The fitness parameters obtained for the transmission (\%) and absorbance $(A u)$ are tabulated in Table (5). From the fitting parameters, it is observed that the value of R-square is close to unity for both transmission (\%) and absorbance $(A u) . S S E$ and RMSE have higher values for transmission (\%) than absorbance $(\mathrm{Au})$. The obtained value of the fitting parameters is obtained assuming the wavelength in $(\mathrm{nm})$ scale.

Table 5: Fitting parameters corresponding to $8^{\text {th }}$ order sinusoidal fitting

\begin{tabular}{|c|c|c|c|c|c|c|}
\hline S.No & $\begin{array}{l}\text { Spectrum } \\
\text { behavior }\end{array}$ & Oil Samples & $S S E$ & $R-$ Square & $\begin{array}{c}\text { Adjusted } \\
R-\text { Square }\end{array}$ & $R M S E$ \\
\hline 1 & \multirow{4}{*}{ 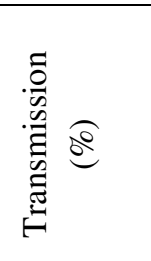 } & Olive oil & $3.579 \times 10^{4}$ & 0.9705 & 0.9703 & 3.141 \\
\hline 2 & & Mustard oil & $3.738 \times 10^{4}$ & 0.9861 & 0.9861 & 3.209 \\
\hline 3 & & Amla oil & $2.943 \times 10^{4}$ & 0.9877 & 0.9877 & 2.848 \\
\hline 4 & & Red palm oil & $4.605 \times 10^{4}$ & 0.9834 & 0.9833 & 3.562 \\
\hline 5 & \multirow{4}{*}{ 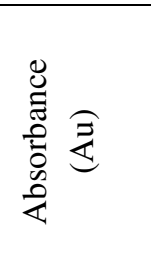 } & Redpalm oil & 49.83 & 0.9777 & 0.9776 & 0.1172 \\
\hline 6 & & Amla oil & 31.45 & 0.9764 & 0.9761 & 0.1084 \\
\hline 7 & & Mustard oil & 29.00 & 0.9756 & 0.9754 & 0.0893 \\
\hline 8 & & Olive oil & 7.22 & 0.9429 & 0.9425 & 0.04463 \\
\hline
\end{tabular}

Thus the generalized form for the developed model is presented in Equation (17).

$f(w l)=\sum_{i=1}^{8} a_{i} \sin \left(b_{i} w l+c_{i}\right)$

Where $200 \mathrm{~nm} \leq w l \leq 1200 \mathrm{~nm}$ respectively.

\section{Conclusion}

A low-cost $U V-V i s-N I R$ sensing setup $(L C S S)$ is developed and presented in this work to analyze transmission (\%) and absorption $(A u)$ from household oils samples. The sensing capability of the developed setup is investigated using four different oil samples. These oil samples consist of olive oil, mustard oil, amla oil, and red palm oil. The transmission (\%) obtained for olive oil, mustard oil, amla oil, and red palm oil is $75.66 \%, 71.10 \%, 69.87 \%$, and $68.12 \%$ at $923.2 \mathrm{~nm}, 924.5 \mathrm{~nm}, 925.9 \mathrm{~nm}$, and $927.8 \mathrm{~nm}$ respectively. Similarly, the absorbance $(A u)$ for olive oil, mustard oil, amla oil, and red palm oil is $0.121 A u, 0.141 A u$, $0.153 \mathrm{Au}$, and $0.163 \mathrm{Au}$ at $920.0 \mathrm{~nm}, 923.0 \mathrm{~nm}, 925.8 \mathrm{~nm}$, and $930.2 \mathrm{~nm}$ respectively. A linear relationship in the wavelength range of $920 \mathrm{~nm}$ to $935 \mathrm{~nm}$ between transmission (\%) and wavelength produce $R^{2}=0.9717$ corresponding to a degree (2). Similarly, the linear 
relation between absorbance $(A u)$ and wavelength produce $R^{2}=0.9997$ corresponding to a degree (2). Finally, an $8^{\text {th }}$ order empirical sinusoidal model is developed for transmission (\%) and absorbance $(A u)$ corresponding to the olive oil, mustard oil, amla oil, and red palm oil. The maximum value of $R$-square corresponding to the transmission (\%) for the developed empirical model is obtained for Amla oil. Similarly, the full value of the absorbance $(A u)$ from the developed empirical model is obtained for red palm oil, which indicates a great response towards the empirical sinusoidal model. Thus the developed LCSS have tremendous potential to analyze various liquids, chemicals, analytes, and oils samples in the $U V-V i s-N I R$ spectrum range.

\section{Acknowledgment}

"This R \& D work is performed under the All India Council of Technical Education (AICTE), National Doctoral Fellowship (NDF), for the AICTE NDF RPS project sanctioned order No: File No.8-2/RIFD/RPS-NDF/Policy-1/2018-19 dated March 13, 2019”.

\section{References}

[1] J. A. Martin-Vela, J. M. Sierra-Hernandez, A. Martinez-Rios, and J. M. Estudillo-Ayala, "Curvature Sensing Setup Based on a Fiber Laser and a Long-Period Fiber Grating," IEEE Photonics Letters, vol. 31, no. 15, pp. 1265-1268, 2019.

[2] D. J. Vazquez, J. E. Ayala, A. C. Guzman, R. Laguna, and R. Aguilar, "Highly sensitive curvature and displacement sensing setup based on an all-fiber micro Fabry-Perot interferometer," Optics Communications, vol. 308, no. doi.org/10.1016/j.optcom.2013.07.041, pp. 289-292, 2013.

[3] J. M. Sierra-Hernandez, A. Castillo-Guzman, R. Selvas-Aguilar, and E. Vargas-Rodriguez, "Torsion sensing setup based on a three-beam path Mach-Zehnder interferometer," Microwave and Optical Technology Letters, vol. 57, no. 8, pp. 1857-1860, 2015.

[4] T. Isoniemi, N. Maccaferri, Q. M. Ramasse, G. Strangi, and F. D. Angelis, "Electron Energy Loss Spectroscopy of Bright and Dark Modes in Hyperbolic Metamaterial Nanostructures," Advanced Optical Material, vol. 8, no. 13, p. 2000277, 2020.

[5] F. Wang, J. Ni, H. Tian, and T. Yang, "Light transmission characteristic analyses of a laser screen in a clear water-based on the Monte Carlo method," Applied Optics, vol. 59, no. 22, pp. 6625-6631, 2020.

[6] C. Guo, A. C.Sedgwick, T. Hirao and J. L.Sessler, "Supramolecular fluorescent sensors: An historical overview and update," Coordination Chemistry Reviews, vol. 427, no. doi.org/10.1016/j.ccr.2020.213560, p. $213560,2021$.

[7] M. A. Kamyabi and M. Moharramnezhad, "An enzyme-free electrochemiluminescence sensing probe based on ternary nanocomposite for ultrasensitive determination of chlorpyrifos," Food Chemistry, vol. 351, no. doi.org/10.1016/j.foodchem.2021.129252, p. 129252, 2021.

[8] A. Pankaew, N. Traiphol, and R. Traiphol, "Tuning the sensitivity of polydiacetylene-based colorimetric sensors to UV light and cationic surfactant by co-assembling with various polymers," Colloids and Surfaces A: Physicochemical and Engineering Aspects, vol. 608, no. doi.org/10.1016/j.colsurfa.2020.125626, p. 125626, 2021.

[9] W. Ji, L. Li, Y. Zhang, X. Wang, and Y. Ozaki, "Recent advances in surface-enhanced Raman scatteringbased sensors for the detection of inorganic ions: Sensing mechanism and beyond," Journal of Raman Spectroscopy, vol. 52, no. 2, pp. 468-481, 2021.

[10] A. Chanakul, R. Saymung, S. Seetha and R. Traiphol, "Solution-mixing method for large-scale production of reversible thermochromic and acid/base-colorimetric sensors," Colloids and Surfaces A: 
Physicochemical and Engineering Aspects, vol. 615, no. doi.org/10.1016/j.colsurfa.2021.126241, p. 126241, 2021.

[11] A. Ramola, A. Marwaha, and S. Singh, "Design and investigation of a dedicated PCF SPR biosensor for CANCER exposure employing external sensing," Applied Physics A, vol. 127, no. doi.org/10.1007/s00339021-04785-2, p. 643, 2021.

[12] A. K. Shakya and S. Singh, "Design and analysis of dual-polarized Au and TiO2-coated photonic crystal fiber surface plasmon resonance refractive index sensor: an extraneous sensing approach," Journal of Nanophotonics, vol. 15, no. 1, p. 016009, 2021.

[13] T. P. Instruments, "What is Ultraviolet (UV) Light?," Teledyne Princeton Instruments, August 01, 2021. [Online]. Available: https://www.princetoninstruments.com/learn/camera-fundamentals/sensorimprovements-to-enhance-uv-sensitivity-from-10-400-nm. [Accessed 05 August 2021].

[14] W. H. Organization, "Radiation: Ultraviolet (UV) radiation," WHO, August 01, 2021. [Online]. Available: https://www.who.int/news-room/q-a-detail/radiation-ultraviolet-(UV). [Accessed August 05, 2021].

[15] J.-F. Güth, A. E. C. Kauling, K. Ueda, B. Florian, and M. Stimmelmayr, "Transmission of light in the visible spectrum (400-700 nm) and blue spectrum (360-540 nm) through CAD/CAM polymers," Clinical Oral Investigations, vol. 20, no. https://link.springer.com/article/10.1007/s00784-016-1755-x, pp. 2501-2506, 2016.

[16] P. Jeevanandam, R. S. Mulukutla, M. Phillips, S. Chaudhuri, L. E. Erickson, and K. J. Klabunde, "NearInfrared Reflectance Properties of Metal Oxide Nanoparticles," The Journal of Physical Chemistry C, vol. 111, no. doi.org/10.1021/jp066363o, pp. 1912-1918, 2007.

[17] M. Tavakoli, S. Jazani, I. Sgouralis, O. M. Shafraz, S. Sivasankar, and B. Donaphon, "Pitching SingleFocus Confocal Data Analysis One Photon at a Time with Bayesian Nonparametrics," Physical Review, vol. X 10, no. doi.org/10.1103/PhysRevX.10.011021, p. 011021, 2020.

[18] H. Kushwah, T. Hans, M. Chauhan, G. Mittal, and N. Sandal, "Development and Validation of the Spectrophotometric Method for the Determination of Menthol," Journal of Applied Spectroscopy, vol. 87, no. doi.org/10.1007/s10812-020-01039-6, pp. 563-567, 2020.

[19] P. T. G. Mayerhöfer, D. H. Mutschke, and P. J. Popp, "Employing Theories Far beyond Their Limits-The Case of the (Boguer-) Beer-Lambert Law," ChemPhyChem, vol. 17, no. 13, pp. 1948-1955, 2016.

[20] Y. D. Zhimin Peng and Y. Ding, "Highly Sensitive, Calibration-Free WM-DAS Method," Sensors, vol. 20, no. 3, p. $681,2020$.

[21] A. M. Nightingale, S.-u. Hassan, K. Makris, W. T. Bhuiyan, T. J. Harvey and X. Niu, "Easily fabricated monolithic fluoropolymer chips for sensitive long-term absorbance measurement in droplet microfluidics," The Royal Society of Chemistry, vol. 10, no. doi: 10.1039/d0ra05330a, p. 30975, 2020.

[22] V. Zholobenko, C. Freitas, M. Jendrlin, P. Bazin, A. Travert and F. ThibaultStarzyk, "Probing the acid sites of zeolites with pyridine: Quantitative AGIR measurements of the molar absorption coefficients," Journal of Catalysis, vol. 385, no. doi.org/10.1016/j.jcat.2020.03.003, pp. 52-60, 2020.

[23] R. India, "Research India: One Stop Solution for your all application,” Research India, January 01, 2010. [Online]. Available: https://research-india.co.in/about_us.html. [Accessed June 07, 2021].

[24] Thorlabs, "Step-Index Multimode Fiber Optic Patch Cables: SMA to SMA,” Thorlabs, Inc., January 01, 1999. [Online]. Available: https://fineabc.top/newgrouppage9.cfm?objectgroup_id=351\&pn=M15L01\#8693. [Accessed June 07, 2021].

[25] G. o. Punjab, "Punjab State Power Corporation Limited," PSEB Head Office, The Mall, Patiala, June 03, 2021. [Online]. Available: https://pspcl.in/. [Accessed June 07, 2021].

[26] E. Casadei, E. Valli, F. Panni and J. Donarski, "Emerging trends in olive oil fraud and possible countermeasures," Food Control, vol. 124, no. doi.org/10.1016/j.foodcont.2021.107902, p. 107902, 2021.

[27] R. Jamwal, Amit, S. Kumari, B. Balan, and S. Kelly, "Spectrochimica Acta Part A: Molecular and Biomolecular Spectroscopy," Rapid and non-destructive approach for detecting fried mustard oil adulteration in pure mustard oil via ATR-FTIR spectroscopy-chemometrics, vol. 244, no. doi.org/10.1016/j.saa.2020.118822, p. 118822, 2021. 
[28] M. González-Locarno, Y. M. Pautt, A. Albis, E. F. López and C. D. G. Tovar, "Assessment of ChitosanRue (Ruta graveolens L.) Essential Oil-Based Coatings on Refrigerated Cape Gooseberry (Physalis peruviana L.) Quality,” Appl. Sci. , vol. 10, no. 8, p. 2684, 2020.

[29] S. S. Andoh, K. Nyave, B. Asamoah, BoniphaceKanyathare, T. Nuutinen, and C. Mingle, "Optical screening for the presence of banned Sudan III and Sudan IV dyes in edible palm oils," Food Additives \& Contaminants: Part A, vol. 37, no. 7, pp. 1049-1060, 2020.

[30] X. Wang, H. Yu, P. Li, Y. Zhang, Y. Wen, and Y. Qiu, "Femtosecond laser-based processing methods and their applications in optical device manufacturing: A review," Optics \& Laser Technology, vol. 135, no. doi.org/10.1016/j.optlastec.2020.106687, p. 106687, 2021.

[31] M. Wang, Y. Yang, S. Huang, J. Wu, K. Zhao, Y. Li, Z. Peng, R. Zou, and H. Lan, "Multiplexable hightemperature stable and low-loss intrinsic Fabry-Perot in-fiber sensors through nanograting engineering," Optics Express, vol. 28, no. 14, pp. 20225-20235, 2020.

[32] M. T. Yaraki and Y. N. Tan, "Recent advances in metallic nano biosensors development: Colorimetric, dynamic light scattering and fluorescence detection," Sensors International, vol. 1, no. doi.org/10.1016/j.sintl.2020.100049, p. 100049, 2020.

[33] Y. Wu, N. Choi, H. Chen, H. Dang, L. Chen and J. Choo, "Performance Evaluation of Surface-Enhanced Raman Scattering-Polymerase Chain Reaction Sensors for Future Use in Sensitive Genetic Assays," Analytical Chemistry, vol. 92, no. 3, pp. 2628-2634, 2020.

[34] W. Zhao, Y. Ma, J. Ye, and J. Jin, "A closed bipolar electrochemiluminescence sensing platform based on quantum dots: A practical solution for biochemical analysis and detection," Sensors and Actuators B: Chemical, vol. 311, no. doi.org/10.1016/j.snb.2020.127930, p. 127930, 2020.

[35] S. Wu, H. Min, W. Shi, and P. Cheng, "Multicenter Metal-Organic Framework-Based Ratiometric Fluorescent Sensors," Advanced Material, vol. 32, no. 3, p. 1805871, 2020.

[36] P. Prosposito, L. Burratti and I. Venditti, "Silver Nanoparticles as Colorimetric Sensors for Water Pollutants," Chemosensors, vol. 8, no. 2, pp. 1-29, 2020.

[37] A. K. Shakya and S. Singh, "Design of dual-polarized tetra core PCF based plasmonic RI sensor for visibleIR spectrum," Optics Communication, vol. 478, no. doi.org/10.1016/j.optcom.2020.126372, p. 126372, 2021.

[38] A. C.Murthy and N. L.Fawzi, "The (un)structural biology of biomolecular liquid-liquid phase separation using NMR spectroscopy," JBC Reviews Molecular Biophysics Neurobiology, vol. 295, no. 8, pp. 23752384, 2020. 